\title{
Enhanced zooplankton abundance in the lee of an isolated reef in the south Coral Sea: the role of flow disturbance
}

\author{
David Rissik, Iain M.Suthers and Christopher T.Taggart ${ }^{1}$ \\ Centre for Marine Science, University of New South Wales, Sydney, NSW 2052, \\ Australia and 'Department of Oceanography, Dalhousie University, Halifax, \\ Nova Scotia B3H 4J1, Canada
}

\begin{abstract}
The effect of flow disturbance on the distribution and abundance of zooplanktonic particles was investigated around an isolated, steep-sided reef, in the south Coral Sea. North-flowing current $>0.3 \mathrm{~m} \mathrm{~s}^{-1}$ caused doming of isotherms by $20-30 \mathrm{~m}$ in the flow-disturbed region at the north-western side of the island. The nutricline and the chlorophyll maximum were at $80-100 \mathrm{~m}$ in the free stream and $50-70 \mathrm{~m}$ in the flow-disturbed region. Over all depths combined, chlorophyll and nutrients were 1.4 times greater in the disturbed region. There was a strong correlation between the depth of the mixed layer, the depth of the chlorophyll maximum and the depth of the peak abundances of zooplankton between 300 and $1000 \mu \mathrm{m}$ equivalent spherical diameter (esd; measured with an optical plankton counter). Slopes of the log-normalized abundance of 19 particle size classes between 300 and $2500 \mu \mathrm{m}$ esd indicated that all particle size classes were more strongly represented in the flowdisturbed region than in the free stream, but that the difference was relatıvely greater for small plankton. This indicates increased production by smaller zooplankton. Using size and taxonomic information from image analysis of net-collected samples, the relative composition of zooplankton did not differ between regions and was dominated by the calanoid copepods Pleuromamma and Acartia, and the cyclopoid copepod Oncaae. Multi-dimensional scaling showed that the particle size community was not significantly different within or between nights, but most flow-disturbed stations were significantly different from the free-stream stations, consistent with current flow. Nutrient uplift into the photic zone in an oligotrophic tropical ocean has a significant impact on zooplankton size structure, and ultimately fish production.
\end{abstract}

\section{Introduction}

Ocean currents that flow past steep-sided islands or reefs form a wake or zone of flow disturbance in the lee of the obstacle (Emery, 1972; Gilmartin and Relevante, 1974; Hernandez-Leon, 1988; Heywood et al., 1990). Flow disturbance associated with sufficiently strong currents can uplift cool, nutrient-rich water into the euphotic zone, resulting in doming of isotherms and increasing primary production downstream of the island (Simpson et al., 1982; Heywood et al., 1990). Chlorophyll may support increased concentrations of zooplankton and enhance secondary production (Heywood et al., 1991). Eddies, or zones of turbulence in island wakes, may also act as retention zones, trapping water and particulates behind the island for significant periods of time (Pingree and Maddock, 1980), and increasing concentrations of planktonic fauna and flora (Gilmartin and Relevante, 1974; Hernandez-Leon, 1988). Enhancement of production and biomass around oceanic islands is termed the island mass effect (Doty and Oguri, 1956), and includes diverse processes such as flow disturbance, island run-off and endo-geothermal upwelling.

Much of the research into the island mass effect has been conducted near highrelief islands with substantial run-off and associated nutrient flux into the ocean (Doty and Oguri, 1956; Dandonneau and Charpy, 1985; Le Borgne et al., 1985; 
Perissinotto and Duncombe Rae, 1990), or from islands with large lagoon systems which contribute to a net outflow of nutrients from the island (Sander, 1981). For this reason, the significance of flow disturbance on planktonic processes has been questioned (Dandonneau and Charpy, 1985; Le Borgne et al., 1985). In this study, we consider the effect of island-induced upwelling resulting from current movement past a low-relief island with a small, shallow lagoon and essentially no terrestrial run-off.

Zooplankton in the oligotrophic Coral Sea (Mackey et al., 1987) are found in low concentrations beyond the continental shelf (Williams et al.,1988). Localized upwelling of nutrient-rich deep waters should therefore greatly influence the distribution and abundance of phytoplankton and, secondarily, zooplankton.

Particle size spectra of zooplankton simplify our perception of the taxonomic and trophic complexity of aquatic systems, and have enabled general patterns of change in the environment to be analysed or predicted (Sprules et al.,1983). The slope of log-normalized models of particle abundance and size classes has been reported to vary between systems with different nutrient levels, between day and night, and between seasons (Rodriguez and Mullin, 1986; Sprules and Munawar, 1986; Ahrens and Peters, 1991). Steeper slopes have indicated a biological response to greater nutrient concentrations, with smaller size classes responding swiftly to increased nutrients. Generally, comparisons of this nature have been between the slopes of wide ranges of particle sizes. Recently, smaller size ranges have been compared $(300-3000 \mu \mathrm{m})$, creating a tool for the investigation of specific plankton components (Taggart et al., 1996).

The aims of this study were to assess the spatial and temporal relationship between flow disturbance and the zooplankton biomass and zooplankton size distribution, around a low-relief cay. In so doing, we identified the biological components of the particle size distribution by determining the equivalent spherical diameter of dominant zooplankton taxa, using sieving, image analysis and an optical plankton counter. We also examined these relationships at different spatial (vertical/horizontal) and temporal scales (within and among replicate nights).

\section{Method}

\section{Sampling area}

Cato Reef $\left(23^{\circ} \mathrm{S}, 150^{\circ} \mathrm{E}\right)$ is an isolated, steeply rising coral reef situated $\sim 375 \mathrm{~km}$ east of Rockhampton, Queensland, in the south-western Coral Sea (Figure 1). The reef rises from $2500 \mathrm{~m}$ deep to the surface over a distance of $\sim 50 \mathrm{~km}$. The $100 \mathrm{~m}$ isobath prescribes an ellipse $\sim 10 \times 15 \mathrm{~km}$ (Figure 1). Two sand cays are associated with the reef, the larger of which is $\sim 600 \mathrm{~m}$ long. North of the sand cays is a lagoon with a mean depth of $-2 \mathrm{~m}$. There is no major region of freshwater run-off from the island.

During 16-19 February 1993, a ship-borne Acoustic Doppler Current Profiler (ADCP) identified a general northward flow of $230 \mathrm{~cm} \mathrm{~s}^{-1}$ (averaged over the $0-120 \mathrm{~m}$ depth range). Approximately $70 \mathrm{~km}$ immediately downstream of the reef, a region of disturbed flow, consistent with that of an island wake, was identified (Figure 1). 


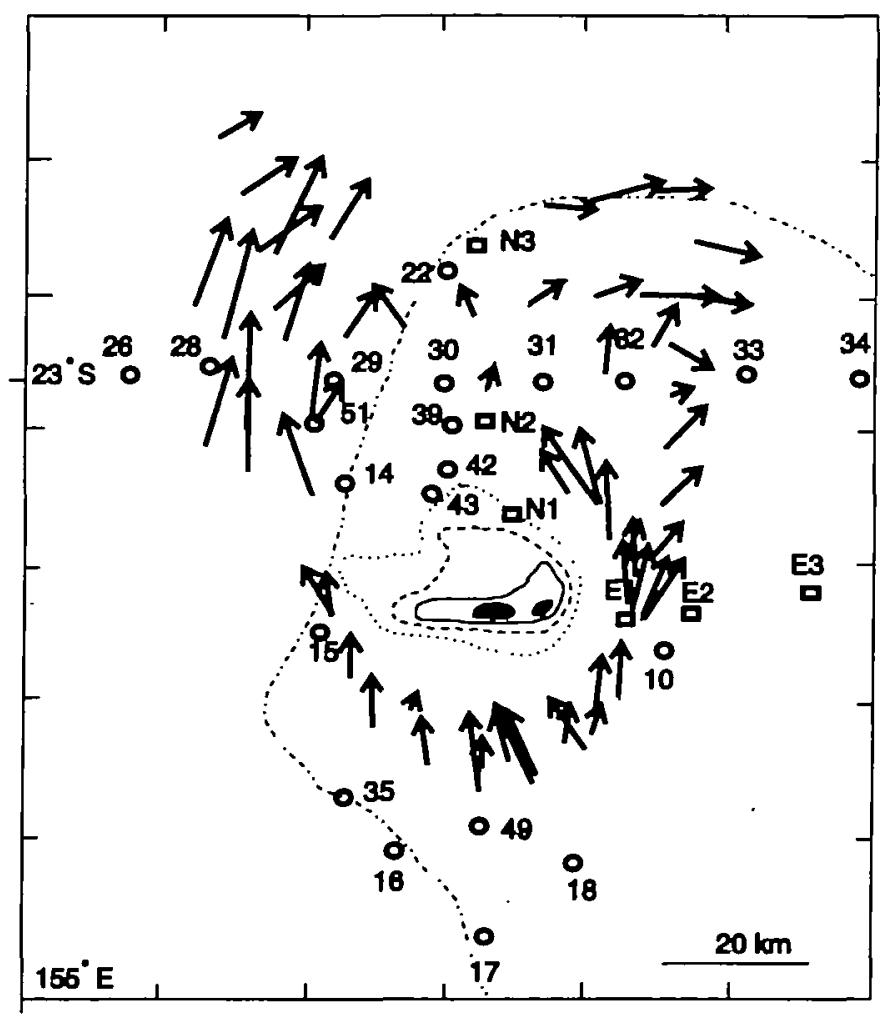

Fig. 1. Map of Cato Island showing the direction of current flow (arrows), indicating a northward current of $0.3 \mathrm{~m} \mathrm{~s}^{-1}$. CTD stations used in Figure 2 (circles) and the six zooplankton sampling stations (squares) E1-E3 and N1-N3 are indicated. Exposed reef is denoted in black, surrounded by $50 \mathrm{~m}$ (-), $500 \mathrm{~m}(. .-), 1000 \mathrm{~m} \mathrm{(....)} \mathrm{and} 2000 \mathrm{~m}(. . .$.$) isobaths. Note stations \mathrm{N} 2$ and E2 used for comparing zooplankton size classes. Tick marks indicate $20 \mathrm{~km}$ distances.

A Neil Brown Conductivity Temperature and Depth recorder (CTD), with a Sea Tech fluorometer and $12 \times 20 \mathrm{l}$ Niskin bottles in a rosette sampler, obtained water samples at six depths (variable intervals) at each of seven stations $(10,15$, $16,17,18,35,49)$ within the free stream and eight stations $(14,22,29,30,31,42$, 43,51 ) in the disturbed region (Figure 1). Samples were analysed for concentrations of dissolved reactive nitrate and dissolved reactive phosphate on board the vessel using a Technicon Auto-Analyser series 2 . Water samples $(2 \mathrm{l}$ ) for chlorophyll analysis were filtered through GF filters which were then frozen in liquid nitrogen. Chlorophyll $a$ was extracted in the laboratory following the methods of Strickland and Parsons (1972), and these data were used to calibrate the fluorometer.

\section{Particle size and zooplankton sampling}

Two transects of three fixed stations were established (Figure 1, Table I): one perpendicular to the free stream, east of the reef in undisturbed water $(E$ transect, 
stations E1, E2 and E3) and the other parallel to the free stream from south to north through the region of flow disturbance ( $\mathrm{N}$ transect, stations N1, N2 and N3; Figure 1, Table I). Each station was sampled at least once on each of three nights (Table I) using plankton and particle size samplers during the period 16-21 February. While steaming between stations, we deployed TUBSS (Towed Underwater Biological Sensing System) in an undulating (tow-yo) manner to collect temperature, salinity, fluorescence and particle size and abundance data.

TUBSS consists of an Endeco V fin fitted with a Focal Technologies Optical Plankton Counter (OPC), an Ocean Sensors OS-100 CTD and a General Oceanics digital flowmeter, each of which transmitted data to the surface through a conducting tow cable. The OPC counts and sizes [as equivalent spherical diameter (esd)] the cross-sectional area of plankton particles which interrupt a coherent light beam $(4 \mathrm{~mm} \times 2 \mathrm{~cm})$ transiting a $2 \times 22 \mathrm{~cm}$ sampling tunnel to a photodiode receiver (Herman, 1988; Sprules et al., 1992). The OPC is electronically designed to output particle sizes into digital bins expressed as a geometric exponential series between 1 and 4096 that correspond to sizes between $\sim 75$ and $\sim 9000 \mu \mathrm{m}$ esd. In practice, sensitivity and typically high particle concentrations limit the smallest reliable size to $\sim 250 \mu \mathrm{m}$ esd (near digital bin 7 ). Likewise, typically low particle concentrations limit the largest practical size to $\sim 2500 \mu \mathrm{m}$ esd (near digital bin 442). In our application, the OPC sampled the water at $5.71 \mathrm{~s}^{-1}$ at the nominal towing speed of 2.5 knots $\left(1.3 \mathrm{~m} \mathrm{~s}^{-1}\right)$. The OPC also provided a measure of light attenuation in the light path that results from water colour and the concentration of particles below the $250 \mu \mathrm{m}$ esd sensitivity range (Herman, 1988). The nominal transit time of $20 \mathrm{~min}$ between stations on each transect allowed between two and four complete undulations (down and up) of TUBSS between depths of $\sim 5$ and $\sim 120 \mathrm{~m}$ using a winch/wire speed sufficient to change sampling depth at a nominal rate of $0.5 \mathrm{~m} \mathrm{~s}^{-1}$. The mean volume of water sampled by the OPC in a 20 min tow was $\sim 7 \mathrm{~m}^{-3}$.

At each station on each transect, zooplankton were collected within three depth strata, 15-45, 45-75 and 75-105 m, using a $1 \mathrm{~m}^{2}$ multiple opening and closing EZNET (Open Seas Instruments, Musquodoboit Harbour, NS, Canada) multiple net/depth sampling device [the marketed version of the Bedford Institute of Oceanography Net and Environmental Sampling System (BIONESS; Sameoto et al., 1980)]. The EZNET was fitted with three $330 \mu \mathrm{m}$ mesh nets, General

Table L. Description of stations and transects. Dates and times (Australian Eastern Standard Time, AEST) in February 1993, station code, latitude $\left({ }^{\circ} \mathrm{S}\right)$, longitude $\left({ }^{\circ} \mathrm{E}\right)$, bathymetry at each station (m) and distance from $100 \mathrm{~m}$ isobath $(\mathrm{km})$

\begin{tabular}{lllllcl}
\hline February 1993 & Station & Latitude & Longitude & Bathymetry & Distance & Starting time (AEST) \\
\hline $16,19,21$ & E1 & 23.25 & 155.68 & 1057 & 6.2 & $21: 26 ; 00: 05 ; 19: 25$ \\
& E2 & 23.23 & 155.77 & 1422 & 14.6 & $23: 44 ; 21: 42 ; 21: 14$ \\
$17,18,20$ & E3 & 23.22 & 155.91 & 1810 & 29.3 & $02: 12 ; 19: 34 ; 23: 21$ \\
& N1 & 23.15 & 155.55 & 294 & 3.4 & $22: 49 ; 00: 10 ; 20: 52$ \\
& N2 & 23.03 & 155.53 & 1441 & 15.8 & $20: 14 ;(00-58-r) ; 21: 45 ;$ \\
& N3 & 22.89 & 155.52 & 1744 & 37.7 & $03: 15 ; 21: 45 ; 00: 22$ \\
\hline
\end{tabular}

r, repeat station. 
Oceanics flowmeters (internal and external), pitch and roll sensors, and a CTD. A $75 \times 75 \mathrm{~cm}$ neuston net fitted with $330 \mu \mathrm{m}$ mesh net and a General Oceanics flowmeter was deployed simultaneously with the EZNET from the side of the vessel. At the nominal tow speed of $2.5 \mathrm{knots}$, each net filtered $800 \mathrm{~m}^{3}$ during each 10 min towing period. After recovery, each net was rinsed into a soft codend (bag made from $200 \mu \mathrm{m}$ mesh net) and samples were immediately fixed in $5 \%$ formalin/seawater. In the laboratory, all larval fish were removed from the samples (Suthers et al., in preparation), and the samples were stored in $2 \%$ formalin/freshwater.

\section{Zooplankton particle identification}

We classified the digitally counted and sized particles provided by the OPC (several hundred digital bins) into a more tractable set of 19 geometric-mean size classes that are based on the truncated value of the square root of the digital bin size. These 19 geometric-mean size classes range from 318 to $2566 \mu \mathrm{m}$ esd in $\sim 125 \mu \mathrm{m}$ size intervals. Concentrations of all particle sizes are expressed as number per cubic metre (no. $\mathrm{m}^{-3}$ ).

To characterize taxonomically the OPC-determined particles, we analysed an EZNET zooplankton sample from each depth at stations E2 (in the free stream) and N2 (in the wake region). Two methods were used to classify taxonomically the OPC-derived size distributions: sieving or image analysis. (i) Each sample was thoroughly rinsed through a stacked series of $1000,850,650,500$ and $300 \mu \mathrm{m}$ square mesh sieves for a period of no less than $10 \mathrm{~min}$. From each of the sieved size classes, eight subsamples of $2 \mathrm{ml}$ were examined. Eighteen dominant taxa and/or sizes were recognized and enumerated (Table II). (ii) The cross-sectional

Table II. List of numerically dominant groups used to characterize size spectra indicated by the OPC

\begin{tabular}{llc}
\hline Taxa & & Size range (esd, $\mu \mathrm{m})$ \\
\hline Chaetognatha & & $1249-1893$ \\
Bryozoan (larvae) & $425-535$ \\
Crustacea & & \\
$\quad$ Copepoda & & \\
$\quad$ Calanoida & Rhinocalanus & $883-1125$ \\
& Acartia & $535-1375$ \\
& Pleuromamma & $648-1761$ \\
& Candacia & $1003-2025$ \\
Cyclopoida & Oithona & $480-610$ \\
& Oncaea & $425-648$ \\
& Corycella & $535-883$ \\
$\quad$ Ostracoda & Copilia & $1083-1162$ \\
$\quad$ Malacostraca, Amphipoda, Hyperiidae & $425-1003$ \\
$\quad$ Mysidacea & & $1375-1631$ \\
$\quad$ Decapoda, Lucifer & $425-535,883-2566$ \\
Cirripedia & $1631-2429$ \\
Invertebrate eggs & $425-535$ \\
Chordata & & $318-425$ \\
& & $535-883$ \\
\hline
\end{tabular}


areas of the 18 taxa were measured using image analysis (NIH Image public domain software). A minimum of 20 individuals of each taxon were measured in this manner. The approximate outline of each individual, including the antennae, but excluding setae, was digitized. The area was converted to esd $(\mu \mathrm{m})$ and then assigned to one of the same 19 size classes used to characterize the OPC data.

\section{Analysis}

All data from TUBSS were aggregated into $2 \mathrm{~s}$ sampling intervals (equivalent to a $1 \mathrm{~m}$ depth resolution and a $2.5 \mathrm{~m}$ horizontal resolution) and then smoothed using an 11-point running average, providing a final resolution of $\sim 5 \mathrm{~m}$ in depth and 14 $\mathrm{m}$ horizontally. The frequency distribution of the 19 OPC-determined particle size classes was estimated for each TUBSS tow at stations E2 and N2 for comparison to EZNET samples from E2 and N2 that were measured by image analysis.

The overall average concentrations of the 19 particle size classes determined using OPC were compared between transects and stations using multi-dimensional scaling (MDS) and analysis of similarity (ANOSIM; Clarke and Green, 1988). The average concentration of each size class was used. ANOSIMs were conducted separately in two stages. We made within-night comparisons using the replicate tows at $\mathrm{N} 2$ (Table I), before comparing all stations, which we had examined at different times of the night. ANOSIM, unlike multiple analysis of variance (MANOVA), does not require data to be normally distributed (Clarke, 1993), which is difficult to meet in data sets with a large proportion of zero values (particularly among the larger size classes). MDS and ANOSIM were performed using the statistical software PATN (Belbin, 1993).

MDS is an ordination technique which reduces a swarm of multivariate data (particle counts $\times$ stations matrix) to fewer dimensions to identity patterns in the data structure. In this paper, stations with different particle size communities are separate. The stress value indicates the degree to which the data are distorted in order to fit the required dimensions. A stress value of $>0.2$ is unacceptable and a value of $<0.15$ indicates a good fit (Clarke, 1993). There are no values on the axes as an MDS scatter can be arbitrarily rotated.

To generate a representative size category for the analysis of variance (ANOVA), all particle size data from N2 and E2 stations were combined and principal components analysis (PCA) was used to group the 19 logarithmic size classes into two size groups. The resulting groups were used for graphical comparison and for analysis of variance. ANOVA was used to compare particle abundance between the northern and eastern transects $(n=2)$, stations (3), depths (4) and nights ( 3 , nested within transect), using $n=2$ undulations per station. Each undulation was divided into the same four depth bins that were sampled using the EZNET and neuston net. In general, all data were heterogeneous (Cochran's test) and were transformed using $\ln (x+1)$ to stabilize the variance. The post-hoc Student's-Neuman-Keuls test (SNK) was used to discriminate among means.

Chlorophyll $a$ concentrations from the daytime CTD transects and particle size classes, and attenuance from TUBSS transects, were tested for correlation under the assumption that chlorophyll $a$ concentrations would not vary diurnally. 


\section{Results}

\section{Temperature and nutrient profiles}

Temperatures in the study area ranged from $26^{\circ} \mathrm{C}$ at the surface to $18.5^{\circ} \mathrm{C}$ at 250 $\mathrm{m}$ depth (Figure 2). The temperature profile across the free stream to the south of the island indicated that water was highly stratified with no uplifting occurring in the free stream. The transect across the disturbed zone to the north of the island indicated that uplifting of up to $30 \mathrm{~m}$ was taking place in the upper $150 \mathrm{~m}$. Full physical descriptions of the flow disturbance and water mass structure are in preparation (Coutis and Middleton, in preparation).

Concentrations of nitrate and phosphate were strongly correlated $(n=102$, $\left.r^{2}=0.93\right)$, and increased significantly with increasing water density $\left(r^{2}>0.65\right)$ and depth $\left(r^{2}=0.57\right)$. Nutrient concentrations were very low above the thermocline, but there were, however, greater concentrations of nitrate and phosphate above the thermocline within the disturbed region by $30-50 \%$ (Figure 3 ).

\section{Particle size fractionation with image analysis}

OPC particle size concentration distributions in both the free stream (E2) and wake (N2) stations show a linear decline in a $\log -\log$ relationship of concentration from the smallest to the largest size classes (Figure 4). A log-log least
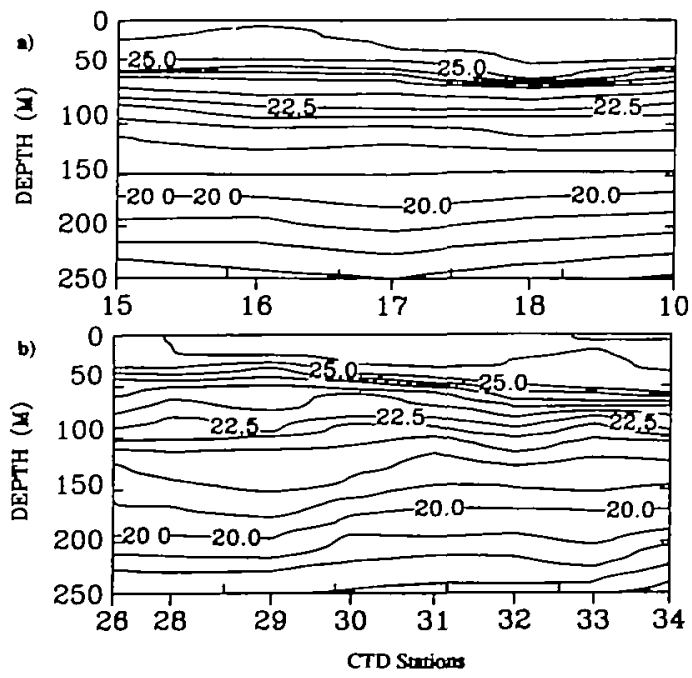

Fy. 2. (a) Temperature isobars upstream of Cato Reef (free stream), showing well-stratified water and a thermocline at $50-60 \mathrm{~m}$. The contour interval is $0.5^{\circ} \mathrm{C}$ and the distance across the section is 56 $\mathrm{km}$. CTD stations are shown in Figure 1. (b) Temperature isobars downstream of Cato Reef (region of flow disturbance), showing a thermocline at $30-50 \mathrm{~m}$, evidence of uplifting of cooler, deeper water by $30 \mathrm{~m}$ at stations 30 and 31 . The contour interval is $0.5^{\circ} \mathrm{C}$ and the distance across the section is 88 $\mathrm{km}$. 

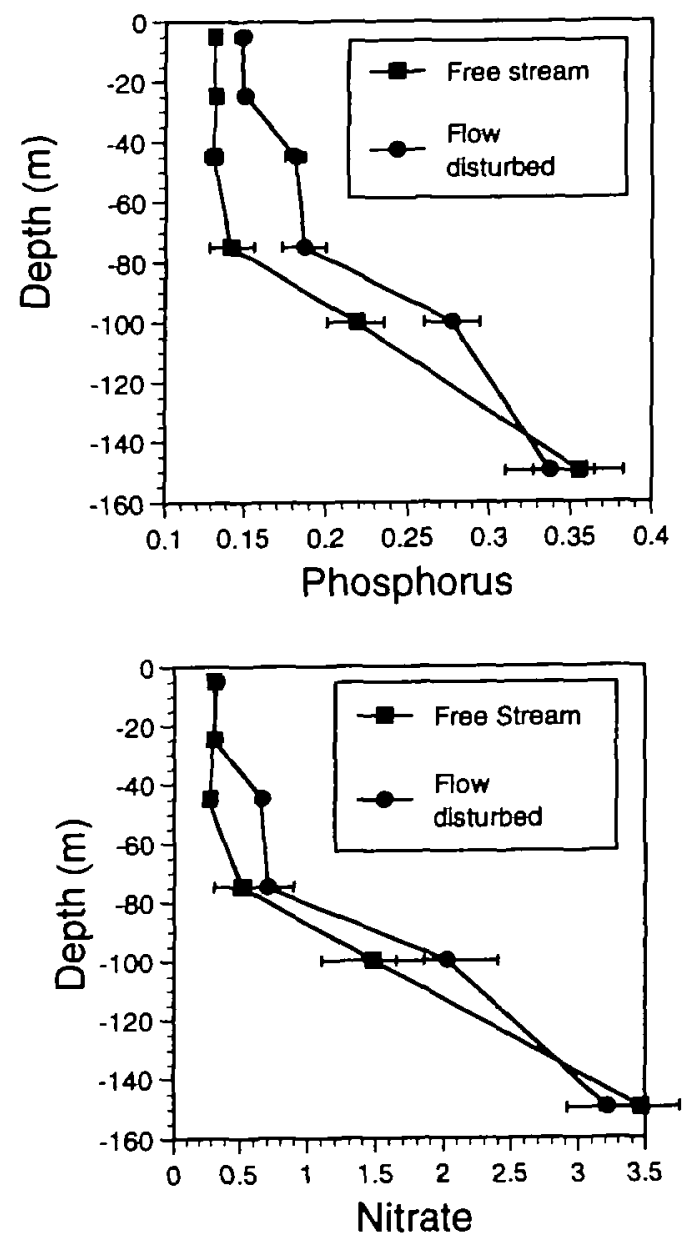

Fig. 3. Comparison of average nitrates $(\mu \mathrm{M})$ and phosphate $(\mu \mathrm{M})$ concentrations with depth at the free-stream and flow-disturbed regions at Cato Reef from CTD stations shown in Figure 1 [seven stations $(10,15,16,17,18,35,49)$ within the free stream and eight stations $(14,22,29,30,31,42,43$, $51)$ in the disturbed region].

squares regression analysis of these data (Figure 5) showed the concentrations to be significantly higher in the disturbed area (flow-disturbed region) than in the undisturbed area (free stream, $y$ intercepts significantly different at $P=0.05$, $t=2.087, n=34)$. The smallest size class $(318 \mu \mathrm{m}$ geometric mean esd) averaged $1800 \mathrm{~m}^{-3}$ in the disturbed area and was twice as abundant as the free stream which averaged $880 \mathrm{~m}^{-3}$. The average concentration of the largest size class $(2566 \mu \mathrm{m}$ geometric mean esd) was observed to be 1.7 times that in the disturbed area. The rate of decay (or slope) in concentration with size was also significantly different $(P=0.001, t=6.06$, d.f. $=34)$ between transects.

EZNET samples from both the $E$ and $N$ transects were numerically dominated by various stages of calanoid copepods, particularly Pleuromamma sp. and 


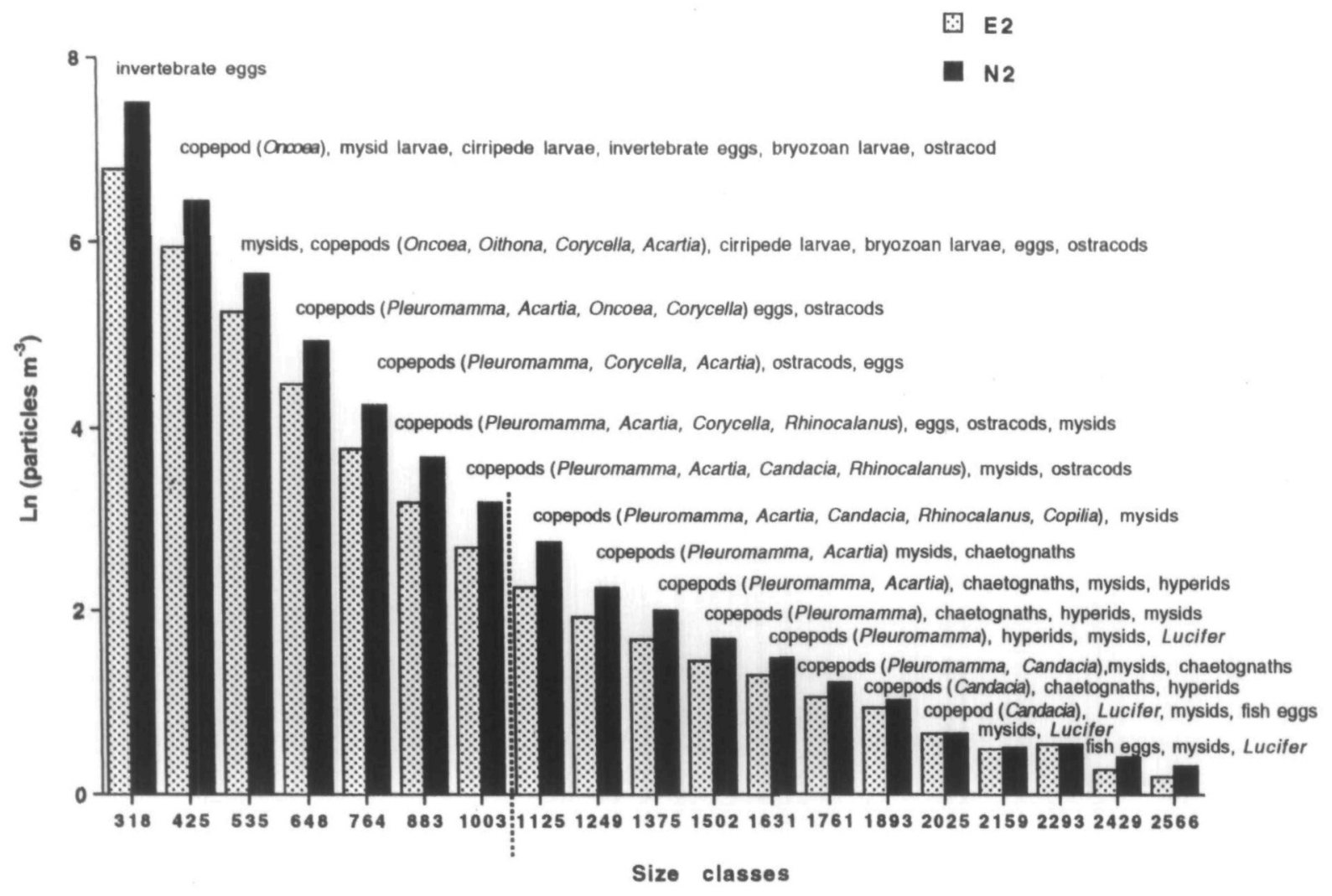

Fg. 4. Log concentration $\left(\mathrm{m}^{-3}\right)$ of particles in 19 size classes from station E2 (stippled bars) and $\mathrm{N} 2$ (solid bars). The mid-esd ( $\mu \mathrm{m}$ ) of each size class is labelled on the $x$-axis. The most abundant taxa associated with each size class are listed above. The dashed line shows the division between particles classified as small $(<1000 \mu \mathrm{m}$ esd) and medium ( $>1000 \mu \mathrm{m}$ esd) by principal components analysis. 


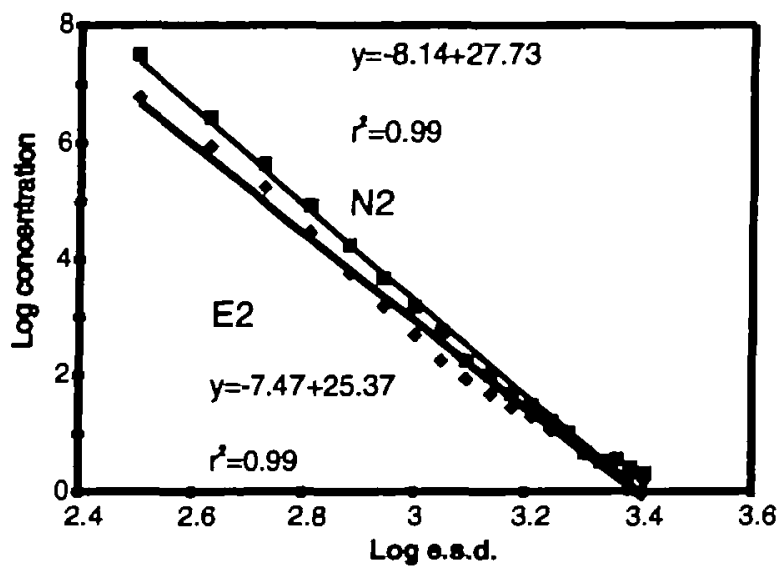

Fig. 5. Log-normalized relationship between particle concentration and particle size class at E2 (free stream) and N2 (wake) stations, showing the greater biomass at N2, particularly for the smaller particles.

Acartia pacifica (Figure 4, Table II), which were common in the 10 size classes between 648 and $1761 \mu \mathrm{m}$ esd inclusive. Other relatively larger size classes of zooplankton $(>700 \mu \mathrm{m})$ were dominated by Crustacea [Mysidacea, Decapoda (Lucifer) and the calanoid copepod Candacia], Chordata (Thalacia), Chaetognatha and fish eggs. The relatively small size classes $(<700 \mu \mathrm{m})$ were dominated by invertebrate eggs, small fish eggs, bryozoan larvae, cirripede larvae and the copepods Oncaea, Corycella and Oithona (Figure 4).

\section{Particle size fractionation with sieving}

Comparison between the esd values of particles assessed using image analysis and the esd of the five different mesh sizes used to fractionate the preserved plankton indicated that the zooplankton retained in the mesh were considerably larger than would be expected from the mesh size alone (Figure 6). Most zooplankters studied were long and thin (copepods, chaetognaths, mysids) and probably passed through the mesh head or tail first.

\section{Among-station variability in particle counts}

There was no significant within-night variation in the abundance of any of the 19 logarithmic size classes in 10 depth bins on either of the two nights at N2 (ANOSIM, night 1: $F=0.95 P>0.05$; night 2: $F=0.98 P>0.05$ ).

Analysis of similarity of particle counts from six stations on each of the three sampling nights showed significant differences between the community size structure of the community in the two transects (Figure 7, Table III). There were, however, no significant differences between the community at $\mathrm{N} 3$ and the 
Island mass effect and particle distributions

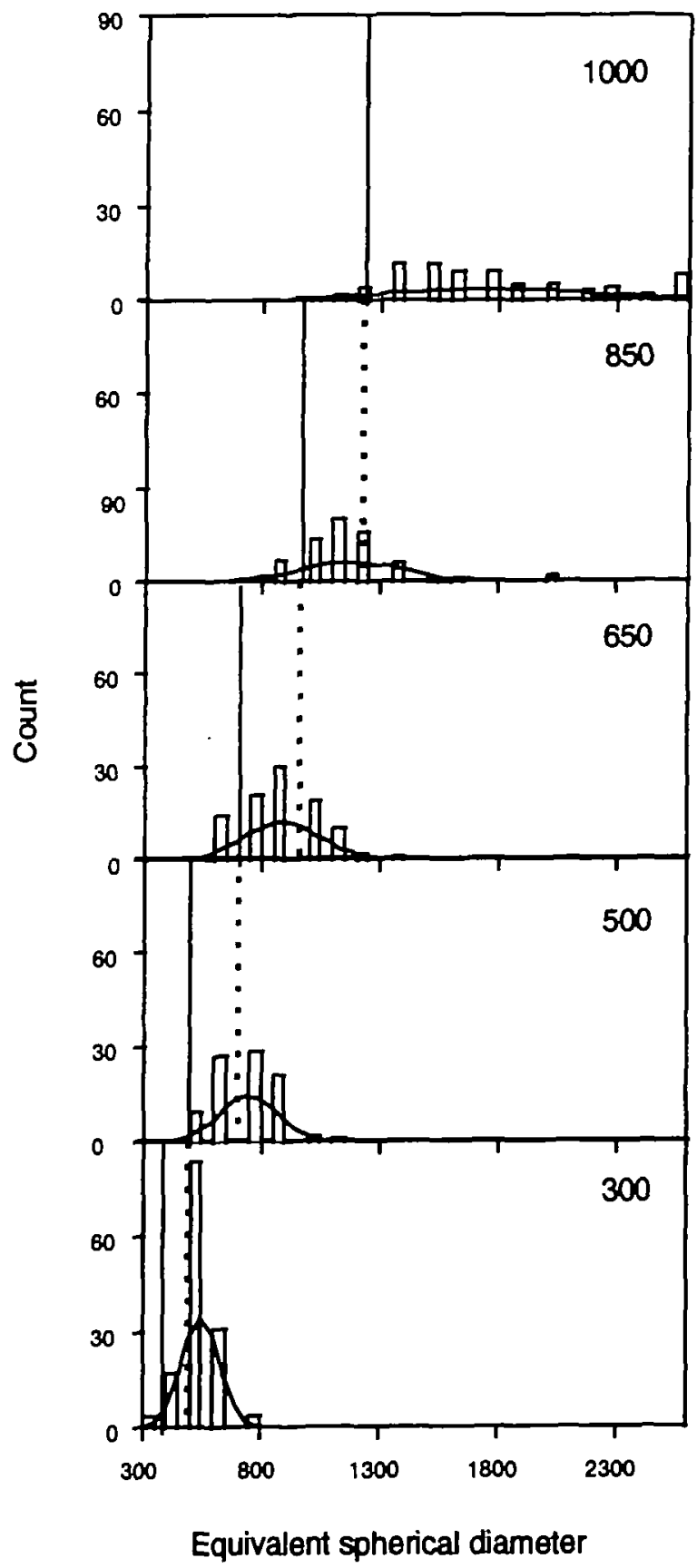

Fig. 6. Frequency histograms of the abundance of zooplankton and particles separated using five sieves with different mesh sizes $(300-1000 \mu \mathrm{m})$ showing that sieving does not produce a narrow range of esd. The range in esd theoretically retained on each mesh should be between the solid vertical line (esd of each sieve's mesh size) and the dotted line (esd of next larger mesh size). The solid bell-shaped curve shows the normal distribution for these data. 


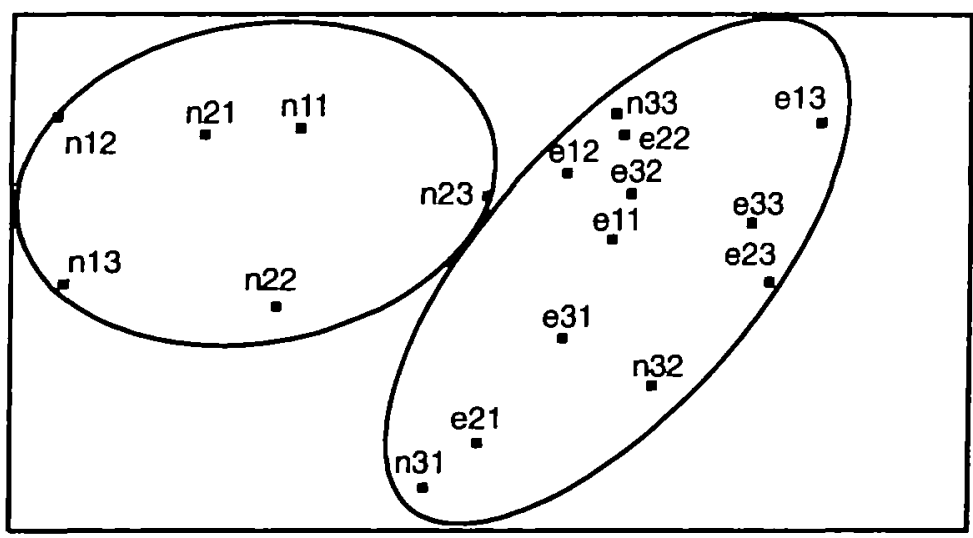

Fig. 7. Multi-dimensional scaling analysis of the mean number of particles per litre of the 19 size classes at each of the six sampling stations over 3 nights. Each data point is labelled station and night as listed in Table I. Stress $=0.0027$. Two significantly different groups are indicated including stations N1 and N2 versus the rest (ANOSIM; Table II).

Table III. Results of ANOSIM comparing particle counts at six stations on each of three nights

\begin{tabular}{ll}
\hline Comparison & $F$ \\
\hline E1, E2, E3 versus N1, N2, N3 & $1.60^{*}$ \\
E1, E2, E3, N3 versus N1, N2 & $2.03^{*}$ \\
N1 versus N2 & 1.12 \\
N3 versus E1, E2, E3 & 1.05 \\
\hline
\end{tabular}

$F$, test statistic.

*Significant difference.

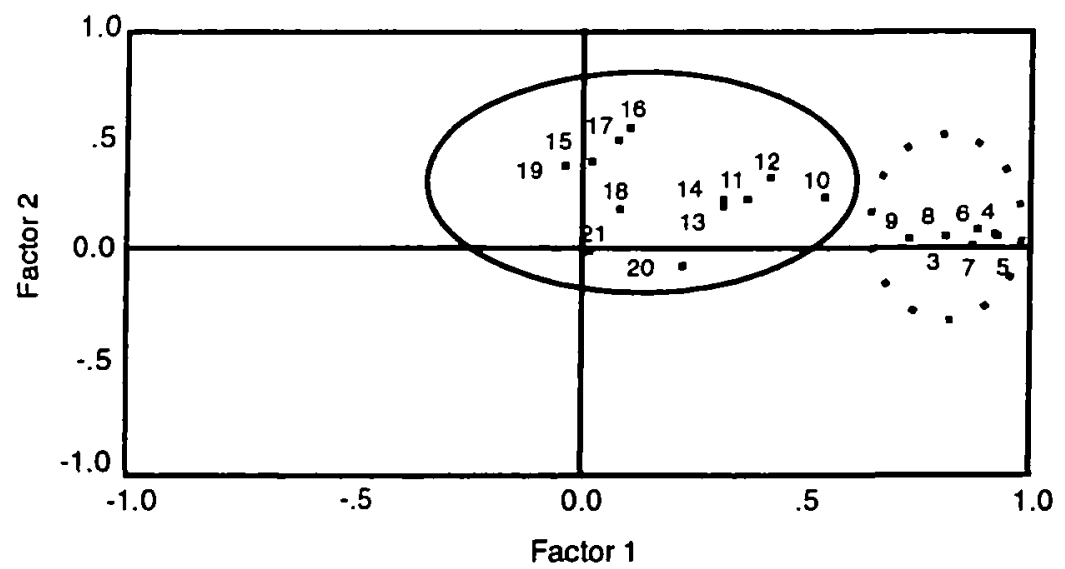

Fig. 8. Principal components analysis of 19 size classes from stations E2 and N2. Each size class is numbered from the smallest analysable class (3) to the largest class (21) as ranked in Figure 1. Similar classes are circled and are referred to as small (solid line) and medium particles (dotted line). 
communities at E1, E2, E3 over the three nights (Figure 7, Table III). The communities at $\mathrm{N} 1$ and $\mathrm{N} 2$ did not vary significantly from each other. The largest proportion of variation was found between the communities at N1, N2 and the communities at N3, E1, E2, E3.

PCA grouped the 19 logarithmic size classes into two distinct groupings of neighbouring size distributions: (i) small particles $(300-1000 \mu \mathrm{m})$; (ii) medium particles $(1000-2500 \mu \mathrm{m}$; Figure 8$)$. The medium-sized particles did not consist of ostracods, but consisted of more elongate zooplankton (chaetognaths, hyperid amphipods and Lucifer, Figure 4).

Analysis of variance showed that there were significant differences in the abundance of small particles $(300-1000 \mu \mathrm{m})$ among transects, stations, depth and nights (Table IV). Most of the variation was due to transect $(55 \%$ of mean square), with depth $(13 \%)$, station $(8 \%)$ and night $(2 \%)$ contributing the least (Table IV). Overall, the flow-disturbed region had a significantly greater abundance of small zooplankton than the free stream. Figure 9 shows the depth distribution of particles at different stations. Stations N1 and N2 were similar and had

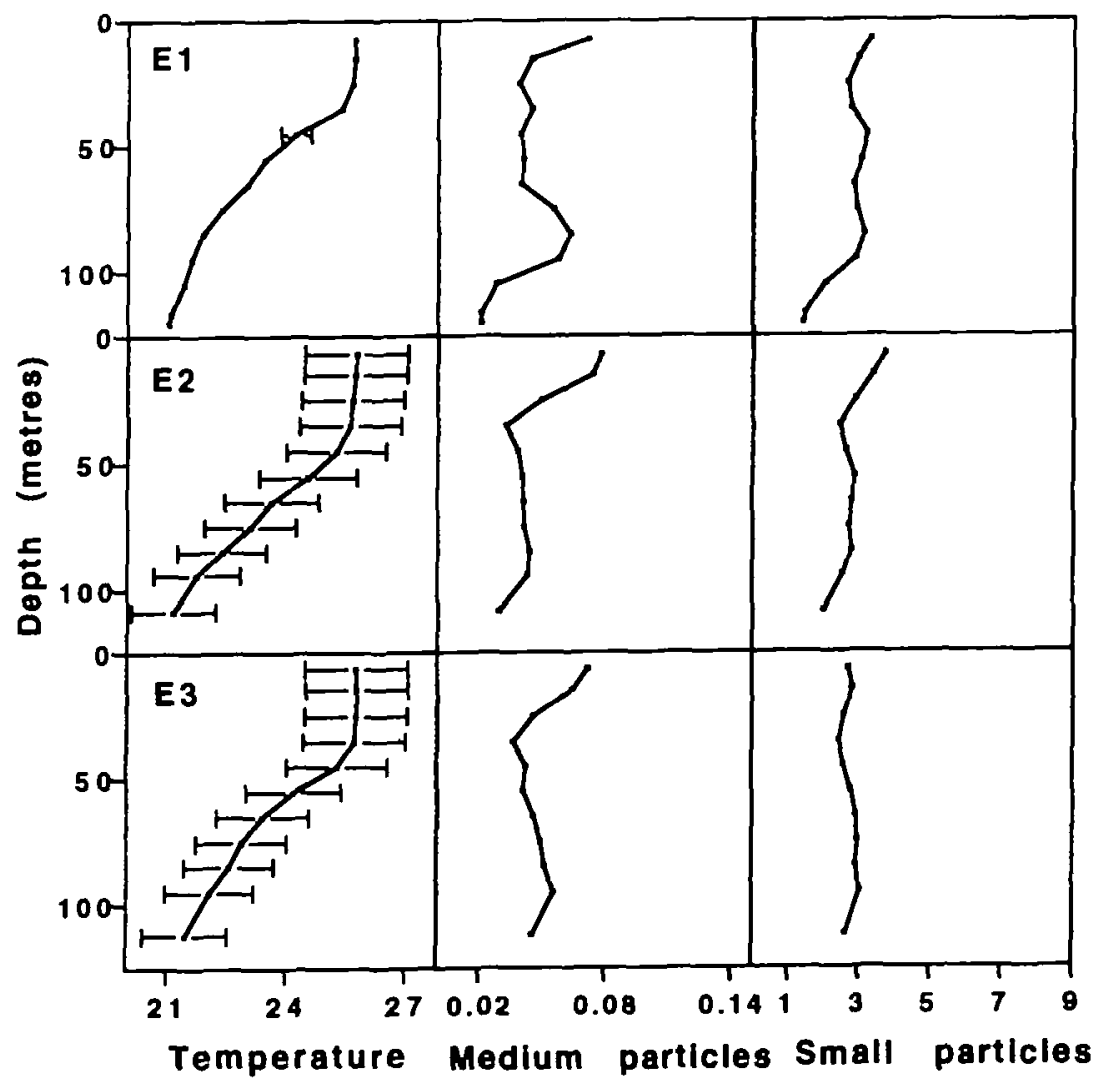

Fig. 9. (a) Depth profiles of temperature $\left({ }^{\circ} \mathrm{C}\right)$, medium particles $\left(\right.$ no. $\left.\mathrm{H}^{-1}\right)$ and small particles (no. $\left.\mathrm{r}^{-1}\right)$ of each of the three eastem (free-stream) stations. Data are averages over the 3 night sampling period. Standard error bars indicate between-night variability. 


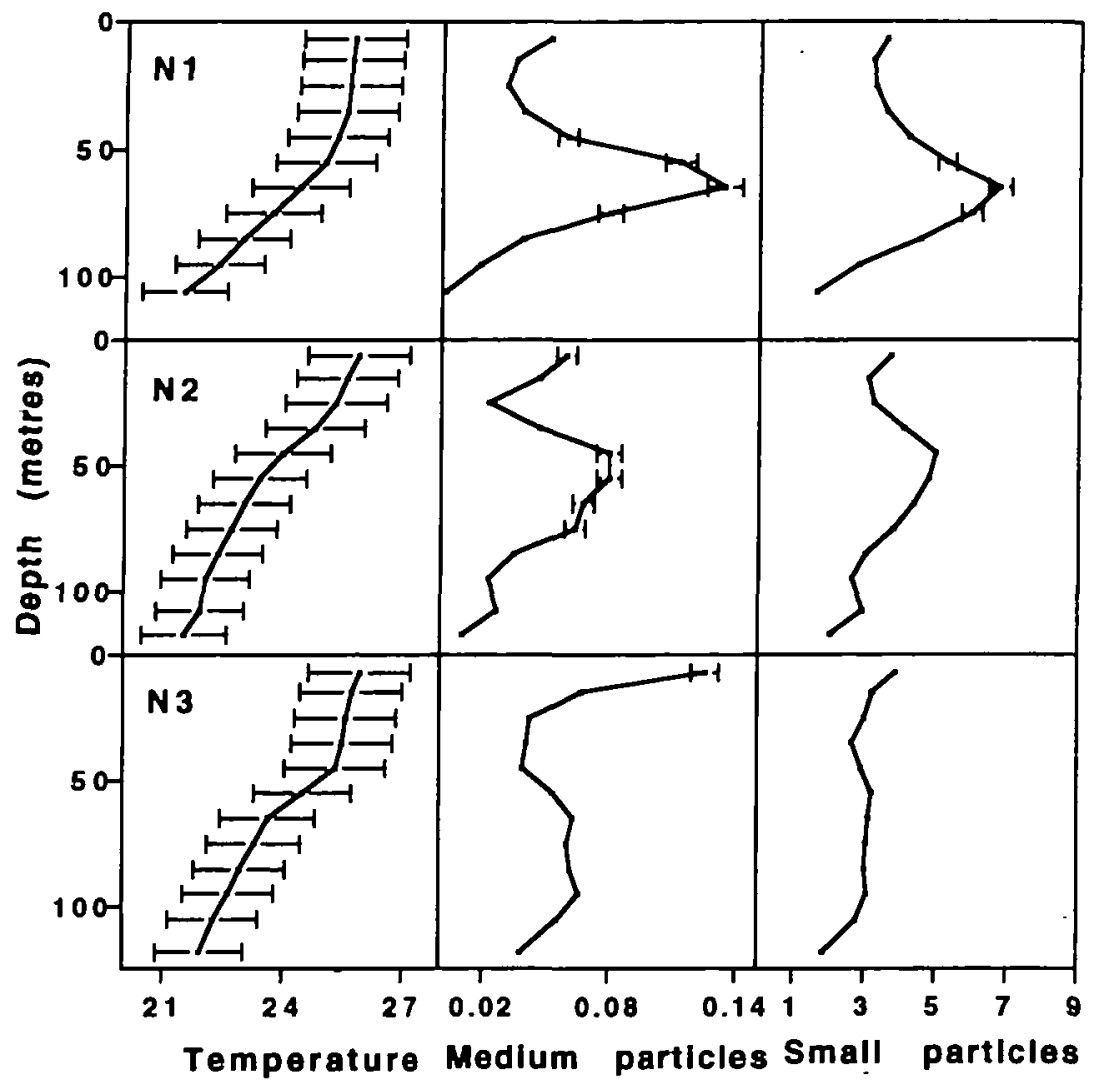

Fig. 9. (b) Depth profiles of temperature $\left({ }^{\circ} \mathrm{C}\right)$, medium particles (no. $\mathrm{I}^{-1}$ ) and small particles (no. $\mathrm{I}^{-1}$ ) of each of the three northern (flow-disturbed) stations. Data are averages over the 3 night sampling period. Standard error bars indicate between-night variability.

significantly greater concentrations of small particles than N3, E1, E2 and E3 which were similar (SNK test, $P<0.05$; Figure 9a).

There was significant interaction between transect and station, and between transect and depth, with greater abundances of small particles at N1 and N2, especially at the thermocline. At station $\mathrm{N} 1$, particle counts were significantly greater at the 16-45 $\mathrm{m}$ depth bin than at 1-15, 46-75 and 76-105 $\mathrm{m}$ (Figure 9a). SNK analysis indicated that at $\mathrm{N} 2$ a significantly greater abundance of small particles occurred between 16 and $75 \mathrm{~m}$ than for the counts either above or below this depth (Figure 9).

\section{Temperature and chlorophyll profiles}

Temperature profiles (from TUBSS) of each station varied among nights, except at station E1, where they remained relatively stable (Figure 9). The change in depth of the mixed layer in the lee of the island showed evidence of islandinduced disturbance. Station N1 had the deepest mixed layer $(55 \mathrm{~m})$, while N2 
Table IV. ANOVA comparing the log abundance of small particles between transects (TRT), station (STN), depth (DPH) and night (NGT)

\begin{tabular}{llclrl}
\hline Source & SS & d.f. & MS & $F$ & $P$ \\
\hline TRT & 0.34 & 1 & 0.34 & 24.96 & $0.00^{*}$ \\
STN & 0.10 & 2 & 0.05 & 3.77 & $0.03^{*}$ \\
TRT $\times$ STN & 0.08 & 2 & 0.04 & 3.11 & $0.05^{*}$ \\
DPH & 0.25 & 3 & 0.08 & 6.05 & $0.00^{*}$ \\
TRT $\times$ DPH & 0.12 & 3 & 0.02 & 3.97 & $0.01^{*}$ \\
STN $\times$ DPH & 0.12 & 6 & 0.02 & 1.46 & 0.21 \\
TRT $\times$ STN $\times$ DPH & 0.11 & 6 & 0.02 & 1.27 & 0.28 \\
NGT & 0.66 & 48 & 0.01 & 16.84 & $0.00^{*}$ \\
Error & 1.89 & 72 & & & \\
\hline
\end{tabular}

SS, sum of squares; MS, mean square; $F, F$ ratio; $P$, probability.

*Significant difference.

had little indication of a well-mixed layer (Figure 9b). Stations N3, E1, E2 and E3 had mixed layers of between 35 and $45 \mathrm{~m}$. The depth of the mixed layer increased further from the island at the eastern side (Figure 9a).

Chlorophyll concentrations were low $\left(\sim 0.05 \mu \mathrm{g} \mathrm{l}^{-1}\right)$ near the surface (between 0 and $20 \mathrm{~m}$ ) in both the free stream and the disturbed region. A strong chlorophyll maximum of $0.42 \mu \mathrm{g} \mathrm{l}^{-1}$ occurred between 60 and $80 \mathrm{~m}$ in the disturbed region, while a chlorophyll maximum of $0.36 \mu \mathrm{g} \mathrm{I}^{-1}$ occurred at $100 \mathrm{~m}$ in the free stream (Figure 10). Average chlorophyll concentrations from five CTD stations in each of the free-stream and the disturbed regions were significantly related to the mean attenuance measured by the OPC at three stations in either the free-stream

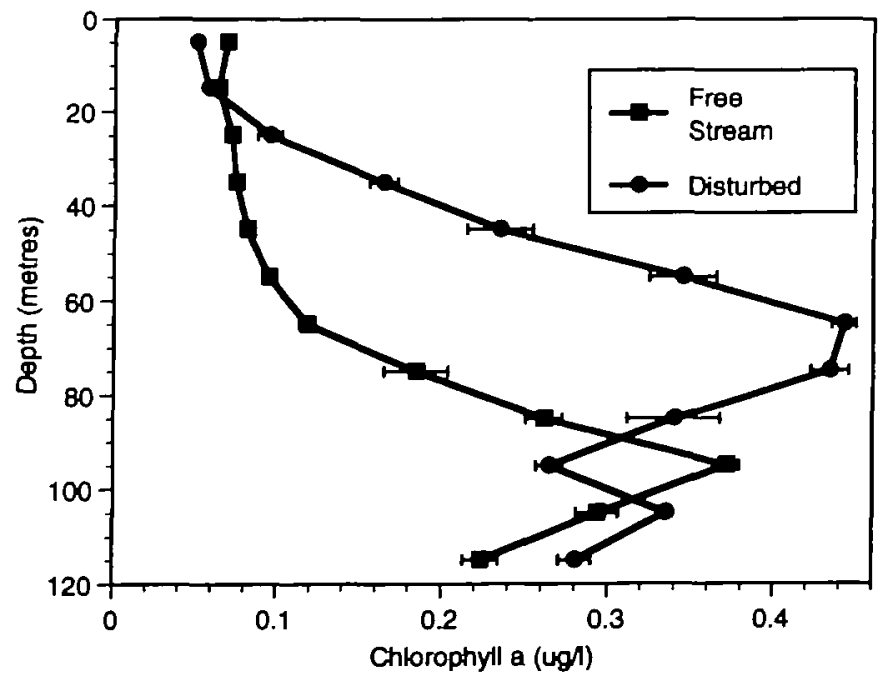

Fig. 10. Comparison of average chlorophyll $a$ concentration $\left(\mu \mathrm{g}^{-1}\right)$ with depth at the free-stream and flow-disturbed regions at Cato Reef from CTD stations shown in Figure 1 [seven stations $(10,15,16$, $17,18,35,49)$ within the free stream and eight stations $(14,22,29,30,31,42,43,51)$ in the disturbed region]. 
Table V. Pearson correlation coefficients of chlorophyll from CTD with small and medium particles and with attenuance from TUBSS. All data are averaged over 12,10 m depth bins. Data are averaged over the disturbed zone from: TUBSS (stations N1, N2, N3), CTD (stations 14, 21, 22, 23, 38). Data from free stream are averaged from: TUBSS (stations E1, E2, E3), CTD (stations 10, 16, 17, 18, 49)

\begin{tabular}{llll}
\hline Variables & Disturbed zone $r$ & Free stream $r$ & $n$ \\
\hline Chlorophyll versus attenuance & $0.94^{*}$ & $0.90^{*}$ & 12 \\
Chlorophyll versus small particles & 0.44 & -0.34 & 12 \\
Chlorophyll medium particles & 0.25 & -0.13 & 12 \\
Small particles versus attenuance & 0.54 & -0.38 & 12 \\
Medium particles versus attenuance & 0.29 & -0.32 & 12 \\
Small particles versus medium particles & $0.81^{*}$ & $0.83^{*}$ & 12 \\
\hline
\end{tabular}

*Significant correlation.

$(r=0.90)$ or the disturbed region $(r=0.94)$. There were no significant relationships between attenuance and small or medium particles in each of the freestream $(r=0.38)$ or the disturbed regions $(r=0.54$; Table $\mathrm{V})$.

The depths of the peak concentrations of small and medium-sized particles (measured using OPC) at stations N1 and N2 appear to be related to the depths of the chlorophyll maximum, with the highest concentration of small and medium particles occurring $\sim 10-15 \mathrm{~m}$ above the chlorophyll maximum.

\section{Particle profiles}

The concentrations of small and medium-sized particles at all stations showed a slight increase towards the surface. Generally, concentrations of small and medium-sized particles were lowest $\left(1-3 \mathrm{I}^{-1}\right)$ below $80 \mathrm{~m}$. The greatest biomass of small and medium-sized particles was found at stations $\mathrm{N} 1$ and $\mathrm{N} 2$, where there was a sharp increase in particle counts (from $2 \mathrm{I}^{-1}$ to between 5 and $7 \mathrm{I}^{-1}$ ) between 45 and $85 \mathrm{~m}$. There was a significant relationship between the peak abundance of small particles and the depth of the mixed layer in the disturbed region, but not within the free stream (Table VI). Concentrations at depths less than $50 \mathrm{~m}$ and greater than $95 \mathrm{~m}$ were $\sim 2.5 \mathrm{I}^{-1}$, which was similar to the counts throughout most of the water column at N3, E1, E2, E3. There was a strong significant relationship between small and medium-sized particles in both the wake region and the free stream (Table $V$ ).

The depth of peaks in abundance of small and medium-sized particles varied between nights at stations $\mathrm{N} 1$ and $\mathrm{N} 2$. The variation in depth was correlated with variation in the depth of the mixed layer at these two stations (Table V). Changes

Table VI. Correlations of the depths of peak values of mean abundance, small and medium particles with the depth of the mixed layer in the wake (stations N1, N2, N3) and the free-stream region (stations $\mathrm{E} 1, \mathrm{E} 2, \mathrm{E} 3) ; n=9$

\begin{tabular}{lll}
\hline Variables & N1, N2, N3 & E1, E2, E3 \\
\hline Attenuance and depth of mixed layer & $0.67^{*}$ & 0.38 \\
Medium particles and depth of mixed layer & 0.54 & 0.27 \\
Small particles and depth of mixed layer & $0.74^{*}$ & 0.03 \\
\hline
\end{tabular}

$* P<0.05$. 
of up to $35 \mathrm{~m}$ were observed between nights at these two stations. Between-night variability was negligible at $\mathrm{N} 3$ and the three free-stream stations $\mathrm{E} 1-\mathrm{E} 3$.

\section{Discussion}

\section{Island mass effect-particle profiles}

Zooplankton were significantly more abundant in the disturbed zone of the island wake than in the free stream. This was particularly evident at depths immediately below the mixed layer at stations N1 and N2 (Figure 9). The zooplankton community appears taxonomically similar between stations N2 and E2 (Figure 3), yet there was a significant difference in the particle size frequency distribution, and the concentration of particles at stations $\mathrm{N} 1$ and $\mathrm{N} 2$ compared to that of station N3 and the three free-stream stations (E1, E2, E3; Table III, Figure 4). This is consistent with ADCP data which suggested that water and particles flowing past the eastern side of the island would be advected towards station N3 (Figure 1).

Islands have been reported to affect the distribution and abundance of zooplankton (Le Borgne, 1985; Hernandez-Leon, 1988, 1991; Heywood et al., 1991). However, most previous studies have been carried out around large high-relief island masses with substantial run-off, or have been influenced by lagoon drainage (Sander, 1981; Simpson et al., 1982; Dandonneau and Charpy, 1985; Perissinotto and Duncombe Rae, 1990). These studies have concluded that island stirring and the associated disturbance do not provide significant concentrations of nutrients compared to run-off or lagoon drainage. We, however, have established increased zooplankton biomass in the lee of a low-relief island with negligible terrestrial run-off, and with a small, shallow lagoon. Similarly, a study around Mare Island in the southwestern Pacific Ocean documented increased zooplankton concentrations in the lee of a flat, lagoon-free island (Le Borgne et al., 1985). There are three plausible reasons why zooplankton concentrations might be elevated in the island wake. These are discussed below.

(i) Advection off reef. Particulate matter and invertebrate larvae may have been washed from the reef, transported to the disturbed area, increasing particle concentrations in the lee of the reef. However, there was no difference in the taxonomic composition found in the free stream and the disturbed region (Figure 4). Image analysis of concurrently collected samples enabled measurement and identification of the abundant particles, and showed that the dominant zooplankton taxa present in the flow-disturbed region and the free stream were similar (Figure 4).

(ii) Retention in island wake. Increased concentrations of mesozooplankton may have resulted from water being trapped in a retention zone formed by eddies or turbulence in the region of flow disturbance. It may also have resulted from zooplankton moving to, and remaining in, areas of increased food abundance. This is dependent on the residence time of water within the disturbed zone, or on the behaviour or buoyancy of the mesozooplankton, which would have had to be such that they counteracted any flow through the turbulent zone. The current velocity 
of $30 \mathrm{~cm} \mathrm{~s}^{-1}$ which prevailed at the time of study is unlikely to result in the formation of a recirculating eddy (retention zone) in the lee of the island (Heywood et al., 1990; Coutis and Middleton, in preparation), and the ADCP data did not indicate the presence of one.

(iii) Increased secondary production. The log-normalized slopes comparing the abundance of different size classes at stations N2 and E2 indicated that significantly greater concentrations of smaller particles $(300-1000 \mu \mathrm{m}$ esd) were found at station N2, but that as size increased, the concentrations of larger particles (2000-3000 $\mu \mathrm{m}$ esd) became similar (Figures 4 and 5). As size and doubling times are related (Dickie, 1972; Kerr, 1974), it is possible that production had increased in the waters immediately north of the reef (N2). Variation in the slope of a normalized particle spectrum has been suggested to be indicative of changed nutrient levels, which have altered the biomass (numbers) of different particle size classes (Bays and Crisman, 1983; Rodriguez and Mullin, 1986; Sprules and Munawar, 1986; Ahrens and Peters, 1991). The differences between the normalized slopes at stations E2 and N2 are indicative of increased production of small particles $(300-1000 \mu \mathrm{m})$. We would expect that concentrations of particles smaller than we examined $(<300 \mu \mathrm{m})$ would also be increased at N2. Broadscale comparisons in the Arabian Sea indicated that increased slopes of normalized particle spectra, between 50 and $6000 \mu \mathrm{m}$, occurred in areas with increased primary production (Piontkovski et al., 1995).

Higher concentrations of nutrients $\left(\mathrm{NO}_{3}, \mathrm{PO}_{4}\right)$ were present below the thermocline in the cooler, denser water mass. Uplifting in the disturbed region (Figure 2) resulted in increased nutrient concentrations which probably caused increased primary production and higher chlorophyll concentrations closer to the surface (Figure 10). Takahashi et al. (1981) describe how nutrient-rich water was moved from $60 \mathrm{~m}$ to the surface by vortices produced by flow of the Kuroshio current past the western flank of Oshima Island. Phytoplankton biomass was reported to have increased due to these increased surface nutrients.

Increased chlorophyll concentrations which resulted from upwelling or uplifting in island wakes have been the subject of some controversy, with some authors suggesting that land-based run-off has greater significance for phytoplankton production around islands (Dandonneau and Charpy, 1985; Le Borgne et al., 1985). In this study and in a study by Heywood $e$ t al. (1990), uplift was associated with increased chlorophyll concentrations in the disturbed zone. Increased chlorophyll concentrations in the disturbed zone off Cato Reef were associated with increased zooplankton concentrations. Genin and Boehlert (1985) also found a greater displacement volume of zooplankton in an area of elevated chlorophyll concentrations on one of two sampling occasions above Minami-Kasuga Seamount, and no increase in zooplankton concentrations where chlorophyll levels were not elevated. Other studies not associated with island disturbances have reported increased concentrations of zooplankton that were correlated with increased phytoplankton (White and Dagg, 1989; Taggart et al., 1996). When increased zooplankton concentrations have been observed in the lee of islands with no associated increase in phytoplankton concentrations, they have been 
interpreted to be the result of grazing (Hernandez-Leon, 1988), unsteady ecosystems (Le Borgne et al., 1985), or weak linkage between the two trophic levels (Le Borgne et al., 1985).

At stations N1 and N2 in the flow-disturbed region, peak zooplankton concentrations occurred $20-30 \mathrm{~m}$ above the chlorophyll maximum. Similar vertical distributions of zooplankton and phytoplankton have been reported, and have been suggested to be due to better nutritional condition (Herman et al., 1981; Napp, 1987).

\section{Attenuance and coincidence}

Attenuance was highly correlated with the abundance of chlorophyll, and not with small or medium particles, and probably reflects phytoplankton distribution. Dower et al. (1992) also found decreased transmission of light immediately below the mixed layer on Cobb Seamount, suggesting that this resulted from increased phytoplankton biomass (production) caused by upwelling of deeper, nutrientrich water into the euphotic zone.

It is possible that concentrations of small particles at stations $\mathrm{N} 1$ and $\mathrm{N} 2$ may have been underestimated due to coincidence. Coincidence occurs when concentrations of particles $>5000 \mathrm{~m}^{-3}$ are encountered, more than one particle breaks the light beam at a time, and are registered as a single large particle (FOCAL Technologies Inc., 1994). Concentrations of between 5000 and 9000 particles $\mathrm{m}^{-3}$ were encountered in $3 \%$ of the particle counts at stations $\mathrm{N} 1$ and $\mathrm{N} 2$, but at none of the other four stations. It is possible that a minor proportion of small particle abundances may have been underestimated and that larger particles may have been overestimated. A variation of this small magnitude would not have affected the results of this study.

\section{Use of image analysis to identify size fractions}

Image analysis was successful in identifying the dominant taxa within each of the 19 logarithmic size classes. Using five sieves to fractionate the zooplankton enabled broadscale identification of the dominant taxa and enabled a rough estimate of the different organisms counted by the OPC. Sieves tended to overestimate the sizes of zooplankton (Figure 6) as elongate organisms are not efficiently size sorted, either lying laterally against the mesh or passing through the mesh head first. The OPC generally measures the larger side profile of each organism (Herman, 1988), and image analysis of dead, stationary zooplankton enables only the maximal side view of zooplankton to be traced and the area to be ascertained. It should be noted that the optical density of the zooplankton would have increased during preservation and live, translucent organisms may not present the same area to the OPC as to our measurements on the computer monitor. It is not known precisely which body parts of zooplankters are recognized by the OPC, compared to the increased magnification under the microscope, and our recognition of all body parts such as antennae and limbs. 


\section{Conclusions}

Most studies examining the effect of island-induced disturbance on zooplankton distribution have used vertical hauls to capture plankton throughout the sampled water column (Yamazi and Wakamiya, 1975; Le Borgne et al., 1985; HernandezLeon, 1988, 1991). This has resulted in over-averaging or smoothing of the data. Use of the OPC in this study enabled vertical and horizontal resolution of zooplankton biomass distribution, and both small-scale and mesoscale variability could be addressed. This study has indicated a positive biological response of zooplankton to purely island-induced flow disturbance. This response (or disturbance) was restricted to depths just below the thermocline.

In an oligotrophic body of water such as the Coral Sea, flow disturbances and related upwelling of nutrient-rich water in the lee of islands and reefs had a significant effect on the distribution and abundance of zooplankton. Increased zooplankton abundance at particular depths can affect the abundance, distribution and health of organisms in higher trophic groups (Suthers, 1996). The relationship between zooplankton size and biomass and feeding by larval and juvenile fish in tropical waters should be examined, as these are an important link to the tuna fishery in these regions.

\section{Acknowledgements}

We acknowledge the financial support of the Australian Research Council, the Department of Industry, Technology and Commerce (DITAC), Focal Technologies, Gary Sprules and Australian Geographic. We especially thank the captain and crew of RV 'Franklin' for their seamanship and co-operation, and the CSIRO support staff. Jason Middleton, Peter Coutis, Rick Royle and Jeff Leis read various versions of the manuscript.

\section{References}

Ahrens,M.A. and Peters,R.H. (1991) Patterns and limitations in limnoplankton size spectra. Can. J. Fish. Aquat. Sci. 48, 1967-1978.

Bays,J.S. and Crisman,T.L. (1983) Zooplankton and trophic state relationships in Florida lakes. Can. J. Fish Aquat. Sci, 40, 1813-1819.

Belbin,L. (1993) PATN Pattern Analysis Package. CSIRO, Australia.

Clarke,K.R. (1993) Non-parametric multivariate analyses of changes in community structure. Aust. J. Ecol., 18, 117-143.

Clarke,K.R. and Green,R.H. (1988) Statistical design and analysis for a biological effect study. Mar. Ecol. Prog. Ser., 46, 213-226.

Dandonneau,Y. and Charpy,L. (1985) An empirical approach to the island mass effect in the south tropical Pacific based on sea surface chlorophyll concentrations. Deep-Sea Res., 32, 707-721.

Dickie,L.M. (1972) Food chains and fish production. ICNAF Spec. Publ, 8, 201-221.

Doty,M.S. and Oguri,M. (1956) The island mass effect. J. Cons., 22, 33-37.

Dower,J., Freeland,H. and Juniper,K. (1992) A strong biological response to oceanic flow past Cobb Seamount. Deep-Sea Res., 39, 1139-1145.

Emery,A.R. (1972) Eddy formation from an oceanic island: ecological effects. Carib. J. Sci, 12, 121-128.

FOCAL Technologies Inc. (1994) Optical Plankton Counter Users Guide. FOCAL Technologies Inc., Nova Scotia.

Genin,A. and Boehlert,G.W. (1985) Dynamics of temperature and chlorophyll structures above a seamount: an oceanic experiment. J. Mar. Res., 43, 907-924. 
Gilmartin,M. and Relevante,N. (1974) The 'island mass' effect on the phytoplankton and primary production of the Hawaiian Islands. J. Exp. Mar. BioL. Ecol, 16, 181-204.

Herman,A.W. (1988) Simultaneous measurement of zooplankton and light attenuance with a new optical plankton counter. Cont. Shelf Res, , 8, 205-221.

Herman,A.W., Sameoto,D.D. and Longhurst,A.R. (1981) Vertical and horizontal distribution patterns of copepods near the shelf break south of Nova Scotia. Can. J. Fish. Aquat. Sci., 38, 1065-1076.

Hernandez-Leon,S. (1988) Gradients of mesozooplankton biomass and ETS activity in the wind-shear area as evidence of an island mass effect in the Canary Island waters. J. Plankton. Res., 10, 1141-1154.

Hernandez-Leon,S. (1991) Accumulation of mesozooplankton in a wake area as a causative mechanism of the 'island mass effect'. Mar. Biol., 109, 141-147.

Heywood,K.J., Barton,E.D. and Simpson,J.H. (1990) The effects of flow disturbance by an oceanic island. J. Mar. Res., 48, 55-73.

Heywood,K.J., Scrope-Howe,S. and Barton,E.D. (1991) Estimation of zooplankton abundance from shipborne ADCP backscatter. Deep-Sea Res., 38, 677-691.

Kerr,S.R. (1974) Theory of size distribution in ecological communities. J. Fish. Res. Board Can., 31 , $1859-1862$.

LeBorgne,R., Dandonneau,Y. and Lemasson,L. (1985) The problem of the island mass effect on chlorophyll and zooplankton standing crops around Mare (Loyalty Islands) and New Caledonia. Bull. Mar. Sci, 37, 450-459.

Mackey,DJ., Szymcjak,R., Tomczac,M.,Jr and Gu,Y. (1987) Effects of mixed-layer depth and an isolated coral reef on the strong complexing capacity of oligotrophic waters. Aust. J. Mar. Freshwater Res., 38, 491-499.

Napp.J.M. (1987) Primary productivity maxima in the Southern California Bight: distribution, predicted depth and nutritional content. Oceanol. Acta, 10, 329-337.

Perissinotto,R. and Duncombe Rae,C.M. (1990) Occurrence of anticyclonic eddies on the Prince Edward Plateau (Southern Ocean): effects on phytoplankton biomass and production. Deep-Sea Res., 37, 777-793.

Pingree,R.D. and Maddock,L. (1980) Tidally induced flows around an island due both to frictional and rotational effects. Geophys. J. R. Astron. Soc., 63, 533-546.

Piontkovski,S.A., Williams,R. and Melnik,T.A. (1995) Spatial heterogeneity, biomass and size structure of plankton of the Indian Ocean: some general trends. Mar. Ecol. Prog. Ser., 117, $219-227$.

Rodriguez,J. and Mullin,M.M. (1986) Relation between biomass and body weight of plankton in a steady state oceanic ecosystem. Limnol. Oceanogr., 31, 361-370.

Sameoto,D.D., Jaroszynski,L.O. and Fraser,W.B. (1980) BIONESS: a new design in multiple net zooplankton samplers. Can. J. Fish. Aquat. Sci, 37, 722-724.

Sander,F. (1981) A preliminary assessment of the main causative mechanisms of the 'Island Mass' effect of Barbados. Mar. Biol., 64, 199-205.

Simpson,J.H., Tett,P.B., Argote-Espinoza,M., Edwards,A. and Jones,K.J. (1982) Mixing and phytoplankton growth around an island in a stratified sea. Cont. Shelf Res., 1, 15-31.

Sprules,W.G. and Munawar,M. (1986) Plankton size spectra in relation to ecosystem productivity, size, and perturbation. Can. J. Fish. Aquat. Sci, 43, 1789-1794.

Sprules,W.G., Casselman,J.M. and Shuter,B.J. (1983) Size distribution of pelagic particles in lakes. Can. J. Fish. Aquat. Sci., 40, 1761-1769.

Sprules,W.G., Bergstrom,B., Cyr,H., Hargreaves,B.R., Kilham,S.S., MacIsaac,K., Matsushita,K., Stemberger,R.S. and Williams,R. (1992) Non-video optical instruments for studying zooplankton distribution and abundance. Arch. Hydrobiol Beih., 36, 45-58.

StricklandJ.D.H. and Parsons,T.R. (1972) A Practical Handbook of Seawater Analysis. Bull. Fish. Res. Board Can., 167, 310 pp.

Suthers,I.M. (1996) Spatial variability of recent otolith growth and RNA indices in pelagic juvenile Diaphus kapalae (Myctophidae): an effect of flow disturbance near an island? Mar. Freshwater Res. 47, 273-282.

Taggart,C.T., Thompson,K.R., Maillet,G.L., Lochmann,S.E. and Griffin,D.A. (1996) Abundance distribution of larval cod (Gadus morhua) and zooplankton in a gyre-like water mass on the Scotian Shelf. In Watanabe, Y., Yamashita,Y. and Oozeki,Y. (eds), Survival Strategies in Early Life Stages of Marine Resources. A.A.Balkema, Rotterdam, pp. 155-173.

Takahashi,M., Yasuoka,Y., Watanabe,M., Miyazaki,T. and Ichimura,S. (1981) Local upwelling associated with vortex motion off Oshima Island, Japan. In Richards,F. (ed.), Coastal Upwelling. A.G.U., Washington, DC.

White,J.R. and Dagg,M.J. (1989) Effects of suspended sediments on egg production of the calanoid copepod Acartia tonsa. Mar. Biol, 102, 315-319. 
D.Rissik, 1.M.Suthers and C.T.Taggart

Williams,D.McB., Dixon,P. and English,S. (1988) Cross-shelf distribution of copepods and fish larvae across the central Great Barrier Reef. Mar. Biol., 99, 577-589.

Yamazi,I. and Wakamiya,M. (1975) Zooplankton in the waters surrounding a new active volcanic island, Nisinosima-Sin To. Univ. Tokyo J. Fish., 61, 71-92.

Received on November 6, 1996; accepted on May 19, 1997 